\title{
Social- and Health-Care Professionals' Meetings with Multiple-Birth Families-Challenges and the Need for More Training and Education
}

\author{
Heinonen Kristiina ${ }^{1,2}$ \\ 1. Savo Vocational College, Educational Services, Services and Welfare, Kuopio 70600, Finland \\ 2. Department of Nursing Science, University of Eastern Finland, Kuopio 70211, Finland
}

\begin{abstract}
Background: A systematic literature review shows there is a need to study how professionals work with multiple-birth families in different kinds of nursing contexts. Objective: The aim is to describe public-health nurses' $(\mathrm{n}=8$ ) experiences of supporting multiple-birth families and to contribute to the understanding of working with such families. Methodology: The qualitative research study is guided by the phenomenological hermeneutic and van Manen's methods have been used. The phenomenon was described through the concept of lifeworld: time, body, relations, and space. The data include participants' interviews and written documents, as well as the researcher's notes. Results: The phenomena of supporting multiple-birth families, as described by public-health nurses, can be expressed by "Recognizing the strain”, "Lightening the load of daily life” and "Targeting special needs”. Conclusions: The social-and health-care professionals met challenges in supporting multiple-birth families, and disclosed their need for training and education. There is a need for more understanding of the unique relevant needs and life situations of such families. Wellbeing and caring involves giving guidance and providing the parents with the special knowledge they need. Further research could concentrate on how evidence-based research guides the work of professionals in multi-professional teams.
\end{abstract}

Key words: Phenomenology, hermeneutic, van Manen, lifeworld, multiple-birth offspring, family nursing, social and healthcare professionals.

\section{Introduction}

Phenomenological research, which is based on phenomenological philosophy, has changed and developed over time. Phenomenology can be understood as a philosophy, as well as a research method in the human sciences. Phenomenology is the philosophical name for the method of investigating or inquiring into the meaning of human beings' lived experiences. The main concepts in phenomenological research are the development of an understanding of meaning, the study of some human concern, lived experience, the lifeworld, and reduction [10]. The researchers' goal is to understand the meaning of

Corresponding author: Heinonen Kristiina, Ph.D., research fields: family nursing science, family nursing care, multiple-birth families. participants' lived experiences. Phenomenology is the reflective study of pre-reflective or lived experiences, and it focuses on interviewing in order to gain understanding of the meaning of the participant's experiences [35-37]. The current study is based on the qualitative research method and guided by the phenomenological hermeneutic [35], and method has been used to describe the lifeworld and the need for support of multiple-birth families expressed by public-health nurses. Multiple-birth families are those that have twins, triplets, or more (ICOMBO 2017; The Finnish Multiple-births Association 2017).

The systematic literature review suggests that there are few studies on fathers' aspect [12, 20, 22, 27] and social- and health-care professionals working with multiple-birth families [22, 25]. Most of the previous 
multiple-birth family studies have concentrated on the transition into parenthood [34], pregnancy and mothering multiples [4-6, 18], parenthood [4, 5, 12, 20, 22, 26], care giving [4, 5, 20, 22], twins’ sleeping [2, 3, 29], and the interactions and relationship between mother and twins and between twins themselves [41, 44, 51].

\subsection{Background}

At the beginning of pregnancy, there is already a difference between being a parent to more than one child of the same age and being a parent of children of different ages. Parents need to be aware of the risks of pregnancy and childbirth [8, 40, 41]. The preterm infants' parents await advice, guidance, and support from professionals [18]. If multiple-birth children are born prematurely, born through a cesarean section or are taken into hospital care there are more challenges for the parents $[6,40]$. If there is a situation where the infants have to be separated due to differences in medical status it could create practical and psychological problem during the neonatal period [6]. The experiences of multiple-birth infant's parents in the early weeks after delivery, were found to express three general themes: the specialness of multiples both positive and negative, the difficulties involved in managing more than one infant, and general attachment concerns [27]. The need for emotional support and guidance on how to organize and take care of several infants' needs, who demand the same mother's attention simultaneously, is immediate. However, other people can also help to organize the amount of work they face in daily life to help manage their situation [16]. There is also a need for support and advice for parents in the prenatal or postpartum periods in dealing with twins' sleeping strategies [12], as well as guidance of midwives regarding the pros and cons of co-bedding for healthy twin babies [2, 3].

Support is important in facilitating a mother's ability to develop a relationship with each twin [1]. If a mother consciously tries to find differences between her multiple infants from the moment of their birth, the children feel clear about their own identities [16]. However, Ref. [50] results yielded a difference in the maternal attachment between twins and singletons; the twins were more often Type B (secure/balanced) attached than the singletons and, based on parental reports, singletons had significantly more behavioural and emotional symptoms than twins. Ref. [4] noticed that, during the first year after delivery, putting one's life on hold that was the primary social and psychological problem for mothers of twins. She described the situation in terms of themes such as power drain, pausing one's own life, striving to relax, and resuming one's own life. Meta-synthesis of mothering of multiples during the first year after delivery includes bearing the burden of children day and night, riding the emotional roller coaster, life saving support, and striving for maternal justice and acknowledging [4].

Parents of twins have general challenges in managing with more children of the same age $[1,4,15$, $16,18,20,22]$. Some specific aspects that mothers encountered problems with were feeding $[18,19,20$, $22,33]$, getting them to sleep [20, 22, 25, 29], and with individualization and equal treatment $[1,18,20$, $47,48]$. Parents were also worried about the lack of time for siblings [18, 22]. Ref. [43] noticed that mothers of twins showed significantly higher levels of parenting stress and depression than mothers of singletons, and were significantly more likely to find parenting difficult and significantly less likely to obtain pleasure from their child (see also Ref. [32]).

Ref. [38] exhorts health professionals practising in hospital and community settings to become aware of the unique needs of multiple-birth women. Refs. [4, 5] states that health-care professionals dealing with mothers of multiples need to be educated about different multiple-birth experiences so that they can provide realistic and helpful guidance for such families. Moreover, Ref. [34] delineates the unique 
needs of multiple-birth children and those of their families, which are still not widely understood or sufficiently addressed by health-care and other professionals (see also Ref. [39]). Nurses, as partners in care at the family and community levels, also have a pivotal role to play in prevention-focused health, education, and social support programs for the identification of parents at risk for psychiatric disorders or problems [32]. Ref. [7] finds it important to educate families, before, during, and after a multiple birth. Parents of twins require more information from professionals, for example, about their own situation, pregnancy and childbirth, breastfeeding, supporting the growth and development of twins, intimate relationships, and coping with everyday life [20-22]. Even though the need for support from social- and health-care professionals in multiple-birth families has been noticed in previous studies, there are hardly any empirical studies about social- and health-care professionals' experiences working in multiple-birth families (see Table 1).

\section{The Study}

\subsection{Aim}

This study aims to describe public-health nurses' experiences of supporting families with twins under five and to contribute to the understanding of working with such families.

\subsection{Methodology}

The qualitative research study is guided by the phenomenological hermeneutic, and van Manen's methods have been used. The concept of lifeworld consists of lived space (spatiality), lived body (corporeality), lived time (temporality), and lived human relations (relationality) [35, 37]. Lived things and objects (materiality) also belong to the lifeworld concept [36].

\subsection{Participants and Data Collection}

Eight public-health nurses, aged between 35 and 58, participated in the present study. Their work experience in maternity clinics (prenatal) ranged between 2 months and 3 years, and in their experience in child health centers, between 5 to 26 years. Most of the public-health nurses have work experience in both places. All of these workers were trained as public-health nurses; one was also a midwife and one a practical nurse. The workplace was informed, and participants volunteered. The open interviews began with these professionals describing support for multiple-birth families and, during the interview, they provided examples. Public-health nurses' permission was obtained. The interviews, which lasted for a maximum of two hours, were tape-recorded and later transcribed verbatim. The data (123 pages) consist of public-health nurses $(n=8)$ open interviews, the documents they sent in writing thereafter, and the researcher's notes.

\subsection{Ethics}

Conducting a literature review led to the discovery of the gap in this research area, which ethically justifies the current study. It is important to respect participants' experiences. Their experiences and knowledge are needed for understanding both the professionals and multiple-birth parents, as well as for developing nursing care. Public-health nurses were recruited to the study on obtaining the positive statement of the University Hospital's Ethics Committee and that of the respective clinics. Only professionals with experience of working with multiple-birth families were included. The public-health nurses could participate during their working day. Participants were provided with all requisite information, including the opportunity to withdraw from the study at any time. Their oral and written informed consent was obtained. Their anonymity was guaranteed, with only the researcher knowing their real names and which data belong to which participant. The researcher interviewed all the participants face-to-face and analyzed the data. 
Table 1 Some examples of research done in multiple-birth family and mention for different kind of support of professionals.

\begin{tabular}{|c|c|c|c|c|c|}
\hline Research & The aim & Participants & Method, data, analysis & Results & Discussion/conclusion \\
\hline $\begin{array}{l}\text { Goshen-Gottstein, E. R. } 1980 . \\
\text { The mothering of twins, } \\
\text { triplets, and quadruplets. } \\
\text { Psychiatry, 43, 189-204. } \\
\text { Israel }\end{array}$ & $\begin{array}{l}\text { To obtain mothers' } \\
\text { reported reactions when } \\
\text { faced with the prospect } \\
\text { of the arrival of } \\
\text { multiple infants and to } \\
\text { study mothers' means } \\
\text { of coping with and their } \\
\text { ways of relating to these } \\
\text { twins, triplets, and } \\
\text { quadruplets. }\end{array}$ & $\begin{array}{l}\text { Multiple-birth families: } \\
n=4 \text { of twins, } \\
n=6 \text { of triplets, and } \\
n=4 \text { of quadruplets }\end{array}$ & $\begin{array}{l}\text { Families were visited at home } \\
\text { monthly and from the infants' } \\
\text { fifth month until their second } \\
\text { year, and, thereafter, at bimonthly } \\
\text { intervals. } \\
12 \text { families were observed until } \\
\text { the children were four to six years } \\
\text { old. } \\
\text { Transcripts were made of the } \\
\text { observations and, later, } \\
\text { categorized. }\end{array}$ & $\begin{array}{l}\text { Mothers were } \\
\text { psychologically unprepared. } \\
\text { It was difficult for them to } \\
\text { meet children's needs } \\
\text { simultaneously; more } \\
\text { ambivalent and negative than } \\
\text { single mothers and } \\
\text { singletons. }\end{array}$ & $\begin{array}{l}\text { Mothers could benefit from } \\
\text { psychological intervention } \\
\text { helping them to work through } \\
\text { their ambivalence about } \\
\text { having more than one baby at } \\
\text { a time. }\end{array}$ \\
\hline $\begin{array}{l}\text { Holditch-Davis, D., Roberts, D. } \\
\text { and Sandelowski, M. } 1999 . \\
\text { Early parental interactions with } \\
\text { and perceptions of multiple } \\
\text { birth infants. } \\
\text { Journal of Advanced Nursing, } \\
30 \text { (1): } 200-10 . \\
\text { USA }\end{array}$ & \begin{tabular}{|l|} 
To examine how \\
mothers and fathers \\
interact with \\
multiple-birth infants \\
and perceive parenting \\
them in the early weeks \\
after delivery, and to \\
compare these \\
interactions and \\
perceptions with those \\
of parents of singletons. \\
\end{tabular} & $\begin{array}{l}\text { Mothers and fathers } \\
\mathrm{n}=7 \text { of seven (twins) } \\
\text { and } \mathrm{n}=1 \\
\text { (triplets) were compared } \\
\text { with those of parents of } \\
49 \text { singleton infants. }\end{array}$ & $\begin{array}{l}\text { Couples were typically } \\
\text { interviewed together three times. } \\
\text { Fortnightly observations of } \\
\text { mother-father-infant interactions } \\
\text { (after the first postnatal } \\
\text { interview). } \\
\text { Home interviews. Qualitative } \\
\text { content analysis was used. }\end{array}$ & $\begin{array}{l}\text { Three themes: the positive } \\
\text { and negative specialness of } \\
\text { multiple births, difficulties } \\
\text { involved in managing more } \\
\text { than one infant, and } \\
\text { attachment issues. } \\
\text { Multiple-birth infants were } \\
\text { left alone more and looked } \\
\text { at, talked to, and held less } \\
\text { often than singletons. }\end{array}$ & $\begin{array}{l}\text { Educating parents about the } \\
\text { issues related to caring for } \\
\text { multiples and have } \\
\text { peer-support. Nurses can play } \\
\text { an integral role in assisting } \\
\text { these families by developing } \\
\text { therapeutic relationships with } \\
\text { them in order to provide } \\
\text { emotional support. }\end{array}$ \\
\hline $\begin{array}{l}\text { Beck, C., T. 2002. Mothering } \\
\text { multiples. A meta-synthesis of } \\
\text { qualitative research. } \\
\text { MCN; The American Journal of } \\
\text { Maternal/Child Nursing, 27(4): } \\
\text { 214-21. } \\
\text { UK }\end{array}$ & $\begin{array}{l}\text { To describe and broaden } \\
\text { understanding to } \\
\text { mothering multiples } \\
\text { during the first year of } \\
\text { life. }\end{array}$ & $\begin{array}{l}\text { Meta-synthesis studies: } \\
\text { Goshen- Gottstein } \\
\text { (1980), Robin, Josse \& } \\
\text { Tourette (1988), } \\
\text { Anderson \& Anderson } \\
\text { (1990), Robin, } \\
\text { Bydlowski, Chen \& } \\
\text { Josse (1991), Garel \& } \\
\text { Blondel (1992), and } \\
\text { Holditch-Davis, Roberts } \\
\text { and Sandelowski (1999). } \\
\text { Parents of multiples }\end{array}$ & $\begin{array}{l}\text { Six qualitative studies comprised } \\
\text { the sample for the meta-synthesis. } \\
\text { Noblit and Hare's (1998) } \\
\text { seven-stage method was used. }\end{array}$ & $\begin{array}{l}\text { The meta-synthesis: five } \\
\text { themes, which help increase } \\
\text { our understanding. } \\
\text { Bearing the burden, Riding } \\
\text { the emotional roller coaster, } \\
\text { Lifesaving support, Striving } \\
\text { for maternal justice, and } \\
\text { Acknowledging } \\
\text { individuality. } \\
\text { The study provides } \\
\text { maternal-child nurses with a } \\
\text { broader, more inclusive } \\
\text { perspective from which to } \\
\text { practice, which could not } \\
\text { have been achieved by } \\
\text { assessing these studies } \\
\text { individually. }\end{array}$ & $\begin{array}{l}\text { Multiple-birth mothers } \\
\text { striving for equality between } \\
\text { their multiples is different } \\
\text { than their striving for } \\
\text { individualization. Clinicians } \\
\text { need to be aware that mothers } \\
\text { are simultaneously grappling } \\
\text { with both these concerns as } \\
\text { they bear the practical burden } \\
\text { of providing childcare and, } \\
\text { during pregnancy, provide } \\
\text { anticipatory guidance. }\end{array}$ \\
\hline
\end{tabular}


Table 1 conitnued

\begin{tabular}{|c|c|c|c|c|c|}
\hline Research & The aim & Participants & Method, data, analysis & Results & Discussion/conclusion \\
\hline $\begin{array}{l}\text { McKenzie, P. } 2006 \text {. } \\
\text { The seeking of baby-feeding } \\
\text { information by Canadian } \\
\text { women pregnant with twins. } \\
\text { Midwifery, 22: 218-27. } \\
\text { Canada }\end{array}$ & $\begin{array}{l}\text { To analyze } \\
\text { baby-feeding } \\
\text { information needs and } \\
\text { the process of searching } \\
\text { for this information, as } \\
\text { described by women } \\
\text { pregnant with twins. }\end{array}$ & $\begin{array}{l}\mathrm{n}=19 \text { women pregnant } \\
\text { with twins }\end{array}$ & $\begin{array}{l}\text { Qualitative data. In-depth } \\
\text { semi-structured interviews. } \\
\text { Transcripts provided the data for } \\
\text { discourse analysis of the use of } \\
\text { two interpretative repertoires. }\end{array}$ & $\begin{array}{l}\text { The four interpretative } \\
\text { repertoires: Frame } \\
\text { information needs; Construct } \\
\text { complex accounts of the } \\
\text { biomedical, experimental, } \\
\text { and personalized authority of } \\
\text { information sources; } \\
\text { Describe the helpfulness of } \\
\text { information sources } \\
\text { independent of their } \\
\text { authority; and Describe the } \\
\text { barriers encountered in the } \\
\text { findings of appropriate } \\
\text { sources of baby-feeding } \\
\text { information in pregnancy. }\end{array}$ & $\begin{array}{l}\text { The professionals can provide } \\
\text { more sensitive support for } \\
\text { women's individual needs } \\
\text { and understanding; and could } \\
\text { provide the most responsive } \\
\text { service for multiple-birth } \\
\text { mothers, who may perceive } \\
\text { different needs than mothers } \\
\text { of singletons. }\end{array}$ \\
\hline $\begin{array}{l}\text { Harvey, M.E., Athi, R., Denny, } \\
\text { E. 2014. Exploratory study on } \\
\text { meeting the health and social } \\
\text { care needs of mothers with } \\
\text { twins } \\
\text { Community Practitioner, } 87 \\
\text { (2): } 28-31 \text {. } \\
\text { UK }\end{array}$ & $\begin{array}{l}\text { To gain insight into } \\
\text { parents' experiences } \\
\text { and to inform service } \\
\text { provision. }\end{array}$ & $\mathrm{n}=7$ mothers of twins & $\begin{array}{l}\text { Audio-taped semi-structured } \\
\text { interviews. } \\
\text { The interviews were transcribed } \\
\text { verbatim and analyzed using } \\
\text { thematic analysis, and qualitative } \\
\text { methods. }\end{array}$ & $\begin{array}{l}\text { Identified themes: } \\
\text { Assumptions vs reality, } \\
\text { worries and concerns, impact } \\
\text { on self and sources of } \\
\text { support. Mothers worried } \\
\text { about preterm birth and the } \\
\text { effect of a multiple birth on } \\
\text { their family life, including } \\
\text { health and wellbeing; other } \\
\text { issues were coping and the } \\
\text { gap between support needed } \\
\text { and received. }\end{array}$ & $\begin{array}{l}\text { The community-based care } \\
\text { received. There is a need for } \\
\text { healthcare professionals to be } \\
\text { better informed about advice } \\
\text { and support needed by } \\
\text { multiple-birth families. }\end{array}$ \\
\hline $\begin{array}{l}\text { Heinonen, K. } 2016 . \\
\text { Supporting multiple-birth } \\
\text { families at home. } \\
\text { International journal of caring } \\
\text { sciences. } 9 \text { (2): 422-31. } \\
\text { Finland }\end{array}$ & $\begin{array}{l}\text { To describe family care } \\
\text { workers' experiences of } \\
\text { supporting multiple } \\
\text { birth families with twins } \\
\text { under five at home and } \\
\text { to contribute to the } \\
\text { understanding of } \\
\text { working with such } \\
\text { families. }\end{array}$ & $\begin{array}{l}\mathrm{n}=11 \text { family care } \\
\text { workers }\end{array}$ & $\begin{array}{l}\text { Open interviews, the document } \\
\text { sent in writing thereafter, and the } \\
\text { researcher's notes. } \\
\text { The phenomenological } \\
\text { hermeneutic study using van } \\
\text { Manen's method and the concept } \\
\text { of lifeworld. }\end{array}$ & $\begin{array}{l}\text { The phenomena described by } \\
\text { family care workers can be } \\
\text { expressed as "Support with } \\
\text { coping”, "Making use of } \\
\text { special information”, } \\
\text { and“Bringing security”. }\end{array}$ & $\begin{array}{l}\text { Meeting at their home gives } \\
\text { an overview of everyday life } \\
\text { and support. Aiding parents' } \\
\text { day-to-day management } \\
\text { meant strengthening their } \\
\text { parenthood by supporting and } \\
\text { guiding and also arranging } \\
\text { some spells of rest for them. } \\
\text { There were special requests } \\
\text { for information and support } \\
\text { concerning taking care of two } \\
\text { children of the same age and } \\
\text { supporting individual growth } \\
\text { and development. }\end{array}$ \\
\hline
\end{tabular}




\subsection{Data Analysis}

The holistic approach depended on understanding the research material and public-health nurses' experiences. The researcher read and listened to the tapes of each interview several times, and discovered some significant experiences of the participants. Different kinds of theme arose from the interviews. Examples include the challenges for professionals to support and advise multiple-birth families, and the professionals' recognition of the need for support for parents, alongside the feeling that they cannot do a lot. The researcher reflected on each sentence uttered by each participant and reported how the participant felt during the experience. An example is "feeling the need for training and more education as a professional". In the selective and detailed phase, the researcher chose the best examples of participants' direct quotations, and re-wrote every experience of each participant. The analysis process then proceeded to the identification of the public-health nurses' unique essential themes. The researcher combined professionals' unique essential themes and organized the phenomena into a disciplinary understanding. The phenomena consist of "Recognizing the strain" (listening to how they are coping and supporting parenthood), "Targeting special needs" (highlighting the need for special information, accessible public-health nurses, and demanding sessions), and "Lightening the load of daily life" (highlighting the need for a support network of close relatives and friends, as well as family care workers) [23, 24, 35, 36] (Fig. 1).

\section{Results}

To illuminate the findings, the phenomenon is exemplified with brief quotes from public-health nurses' experiences.

\subsection{Recognizing the Strain}

Recognizing the strain consists of listening to how they are coping and supporting parenthood.

\subsubsection{Listening to How They Are Coping}

As part of the experience of lived body, public-health nurses need to recognize the strain of the parents and, in particular, listen to how they are coping and give

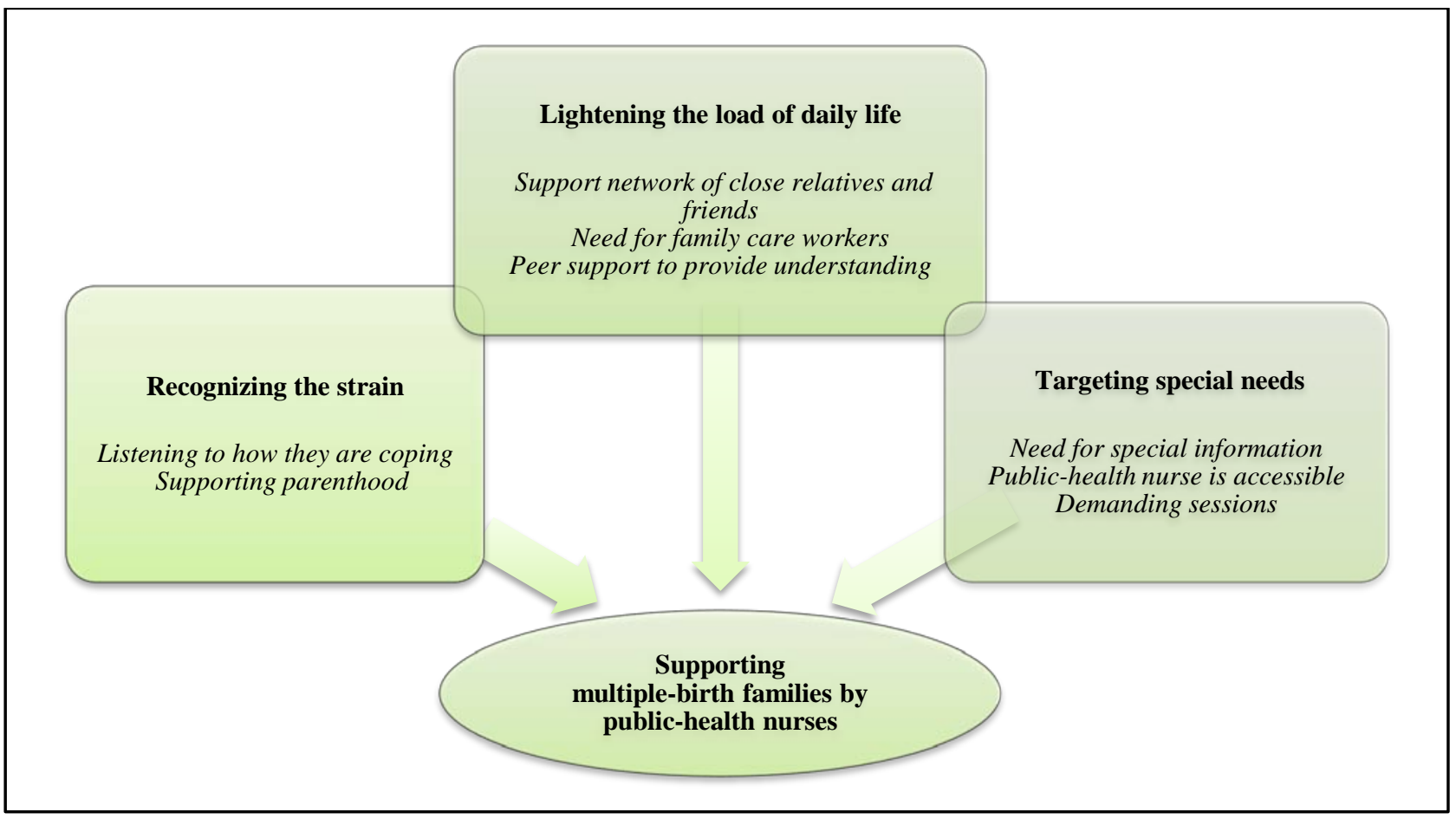

Fig. 1 The phenomena supporting the lifeworld in multiple-birth families as described by public-health nurses. 
support to the parenthood. Parents need a lot of support and encouragement to embrace their life situation. They also need support to take time for rest, which is sometimes hard to find given their daily workload. After the birth of twins, an extra pair of hands could help in their life. This was a subject that led parents to try to get public-health nurses to help in organizing help at home, and the experience of the body of public-health nurses is shaped by the parents' life at home being full of childcare. According to public-health nurses, parents were temporarily thrown into a totally new life situation, as the birth of two children in a family is different from the birth of one child. There are related issues of coping and the smooth running of daily life, for which parents can be prepared in advance. From the corporeality, relationality, and experiences of specialty public-health nurses on the first home visit, when the client relationship was still being built, it could be observed that the parents were shy of the public-health nurse, but also that the babies were a source of joy and pride. Observing the home situation also sometimes provides information.

"It is a big change, the birth of a baby, and when two babies arrive, then there is, absolutely, this question of coping and how the family experiences the situation and how daily life will go. Multiple babies mean more work for the parents. So, in a way, if support is needed in taking care of just one baby, then. It's double the amount of support!”

"If there are two babies, then, although they proudly show their babies and are certainly a bit hesitant, thinking "have we done things right?"...natural that they are tired... if their home is in tiptop shape...You know they tire themselves out with this taking care of the home".

Again these and bodily experiences of public-health nurses on visits to the child welfare clinic were found to be important for parents. Information about the children's welfare and health, as well as the fact that they could call the clinic and ask about things and that the nurse had time to listen, was especially important to the parents. This meant that there was also a professional relationship between public-health nurses and parents. Public-health nurses' experiences of body and lived time meant being surprised at how the parents coped. There is a least twice as much childcare and other work, but the parents seemed to have sufficient resources for their life situation.

"...the expertise ... the health issues are OK, the question is checked and the parents do not need to worry. The parents here, too, certainly appreciate the opportunity to call and visit the clinic. They can also unburden their feelings and the details of their situation. Actually, I myself always had a bit of a skeptical feeling all the time, like somehow I was always asking, can you really cope, and really wondering, where do they find the resources?”

\subsubsection{Supporting Parenthood}

Temporality involves public-health nurses supporting the parents in different stages of parenthood. Parents need advice and emotional support during the pregnancy as well as after birth. The lived body of experience of public-health nurses find the situation of parents being available with two babies who keep calling for various needs. They find it important to temporarily stop giving time to children, as daily life was also full of other tasks at home. Understanding the relationship between parent(s) and children and the twin-twin relationship is important. In terms of the experience of time, according to public-health nurses, it was felt that parents only had the chance to pay more attention to the individuality of the children later, when life had settled down. In the experience of human relations, parents should also have time to focus entirely on interaction with their children. It was considered important for the child's later development and a factor strengthening the parents' ability to cope. It was also the parents' right.

“... during the baby period, they're up to their eyes in work, then, later, it's easier to see how lovely that 
there are two and how they are nevertheless individuals and different and they are important to each other ... to be absorbed in talking and playing and being face to face and that for that, too, there would be time ... they should also have the right to that kind of pleasure and enjoyment of their own children...”

In their experience of body, time, and relationships, they highlighted consideration for and understanding of a child's personal growth and development and their finding their own hobbies. A twin should be allowed to grow in peace as an individual and a person, at his or her own pace, without being compared with the other twin. Parents were also advised to find hobbies that corresponded with the child's own interests.

“... and you really must not do everything in the same way with both children, according to a certain pattern, but so they really develop as individuals...then the comparison too, one may be a bit sharper and then the other has more abilities and one grabs your hair a bit more...one of them, say, to the sports club or (the other) to the music club...”

A public-health nurse had observed unfair treatment between the children in relation to parent-child interaction and described this as a bodily experience. They mention that these situations did not only occur in multiple-birth families, but also with parents of children of different ages. In the experience of body and human relations, the nurse stressed the need to treat children equally and fairly. Recognizing the temperament of each child was considered important in supporting its development.

"...that one of the children somehow very easily, say, makes the mother angry or irritated. And the other is of the kind that gets petted and hugged more. But they're not often like that, but of course it can happen in a group of siblings in any case ... treating them as equals, so that one is not held up as the good one ... since they are different in their personalities.”

There were also times when support was needed more and, in their experience of the body and of human relations, the public-health nurses find the need for support by parents important when the children were at a defiant bodily age. Handling the situation with two children also takes energy from the parents. Over time, this meant more support with upbringing was needed than in families with children of different ages because there were more children at this stage.

“...support with upbringing must be given to them, too. And to them maybe even a bit more because there are two, there's already somebody there to fight, so usually there are more fight situations...”

\subsection{Lightening the Load of Daily Life}

Lightening the load of daily life consists of support network of close relatives and friends, need for family care workers and peer support to provide understanding.

3.2.1 Support Network of Close Relatives and Friends

In public-health nurses' experiences of the body and human relations, they find support from a network of close relatives and friends to be important to the parents. They were worried about parents who do not have people around them. A support network is important to all families and it could also decrease lonely bodily feelings. The public-health nurses also suggested that they could see that the parents were tired and seen the need to help to try to find a solution to this situation by getting help to the family. However, sometimes there is such strong bodily feeling that your own attempts to do as much as possible are still too little. They really like to help more but lack the tools to do so. They even find it important to being present in this relationship, listening deeply and giving support to solve the situation together with parents.

“...this means also that the close family members can and like to help. If the grandparents are old and live away or have died and the multiple-birth family dose not have any friends in the same area, the situation is already hard. When you are alone where to 
get help when you need it? The supporting net of close family members supports families to manage and eases the daily life in all families, but, of course, it is especially important in multiple-birth families...”

"...even I can see that the mother is tired... I do not have any ways to help her, the only thing that can be done in the child welfare clinic is listening and discussing together and trying to think about and find the best solution. Sometimes there are close family members, like grandparents and relatives, who can come to help..."

\subsubsection{Need for Family Care Workers}

The large supportive network could lighten the load of daily life. In child-care clinics it is also important to discuss the view of relations and body with the parent when there is a close family member available to help. There is a need for homecare in multiple-birth families because parents often have to learn how to take care of children, while there are also challenges to handling home care. In the experience of speciality, the tasks at home also burden families’ daily life.

“...there is also learning in household work and when we know what the baby and two babies bring to the family ... So, it is important that there is someone who can take care of daily routines at home, and that there is food, washed laundry and should make sure that both babies can spend time in parents arms..."

The situation at home is very sensitive and, in a bodily experience, some of the public-health nurses thought that it would potentially be better if the family got help from someone other than a close family member. This is because sometimes the situations at home can come to a head with close family members and that is why an outsider could be better.

“...the parents in multiple-birth families would like to have neutral person to help them ... the situations can come to a head when you are tired or feeling that mother in law knows more and can do much better than them other..."

\subsubsection{Peer Support to Provide Understanding}

Peer support involves bodily and relational aspects that share a very deep understanding with each other, which can only be found among this kind of family with multiple children. Public-health nurses' bodily experience is that those parents cannot find such support and understanding anywhere else. Peer support has been successful and is the best way to get concrete support and advice as a multiple-birth parent.

Public-health nurses had also referred parents, with their permission, to a peer support group. This enabled them to exchange good practices and expanded their support network. From the perspective of relationships, peer support provides an opportunity to see the life of families in totally different aspect. In the experience of relation, public-health nurses felt that the possibility to share your own life with someone else in the same life situation also provides the experience that other parents have same kind of questions and problems as oneself.

“...they think of surprisingly good tips and solutions for systems, how they deal with shopping, social visits, getting dressed, going out, sleeping, meals... that was why I wanted to advise them to talk among themselves and get them together...”

“...the peer support brings the closeness to adult people and the same life situation together... same problems (laughing) ... it means that I am not alone and this is quite usual and normal... it could clarify your own thoughts or when you hear another person's story... people who have the same situation are the best at understanding each other's situations...”

\subsection{Targeting Special Needs}

Targeting the special needs consists of accessible public-health nurses, the need for special information, and demanding sessions.

\subsubsection{Accessible Public-Health Nurses}

The public-health nurses find it important to be accessible to parents. The daily life and routine of multiple-birth families postpartum was focused on the home, which meant increased home-centeredness. Public-health nurses also noticed this. Spatiality can 
be seen in the way in which the parents' world tends to contract, becoming more limited.

"...the first months are somehow so full that, at that time, the parents do not really want to go anywhere... they just concentrate on somehow getting the system to work...”

The public-health nurses find it important that they are accessible to parents. In meetings, as relational and bodily experiences with public-health nurses, parents discussed more situations where they needed help because these situations drain their energy and resources. However, public-health nurses, in their deep bodily experience, felt that parents were really happy having two or three babies.

“...There are also easy twin children but, there are more things which take resources. But I have to press that parents are really happy that they have two or three babies, it is so rich and special to themselves..."

In the view of specialty, social and health professionals meet parents in a variety of contexts, such as their own offices, as well as roughly twice at homes of multiple-birth families. Most health and social professionals prefer meeting these parents in their offices. Visits to the child welfare clinic were found to be important for parents. Information about the children's welfare and health, as well as the fact that they could call the clinic and ask about things and that the nurse had time to listen, was important to the parents. In supporting the parents, presence, sympathy, and showing understanding were considered important in the bodily experience of public-health nurses.

“...the expertise ...health issues are $\mathrm{OK}$, the question is checked and the parents do not need to worry. The parents here, too, certainly appreciate the opportunity to call and visit the clinic. They can also unburden their feelings and the details of their situation...”

“...I cannot do anything in some situations, so it's enough that I give them my understanding ... that half helps the person ... Listening is important, understanding can be shown, say with a word or a nod. Sometimes I have taken their hand or gone to sit next to them ... Eye contact, too, can be supported. On a weekday, even a surprising smile ... and time... try to organize them time to come together and when it is the easiest time for them. So the father can also come and help the mother...”

\subsubsection{The Need for Special Information}

(1) Preparing to provide support

Public-health nurses have observed that meeting the needs of parenthood in multiple-birth families required special knowledge. Providing help in the home must already be planned during pregnancy, and preparing parents for parenthood was viewed as important.

“...family coaching-type ... already thinking beforehand what kinds of challenges are being a multiple-birth family brings and in what way you could prepare for that and how we could provide the care support...”

(2) Noticing individuality

A public-health nurse spoke about how the different temperaments of several people also presented a challenge from a nursing perspective. The children were almost always in interaction situations at the same time. Parents need guidance in order to know how to treat their children individually and give them enough attention.

"...your own pace then has to be adapted to the child's pace ... when there are two of them and if they are also different, it's something of a challenge, then if the mother, what kind of temperament does she have ... the parents are, I think, from the start a little worried about how they can treat them as individuals, when they are always there together, and give consideration to their personal characteristics and devote themselves to one child at a time...”

(3) Guidance for nights needed

As a result of the night-time stress, parents needed support, understanding, and sympathy. The new life situation and changes also affected the parents' alertness.

“...the parents also wake up very often even though 
the babies had not woken up. The life situation is so new..."

In multiple-birth families, finding a day and night rhythm for both infants of the same age is more difficult than in families with children of different ages, and the differences are great when the children are small. This requires the parents to sustain round-the-clock preparedness with regard to infant care, which demands a lot of flexibility, as well as patience. Being in a constant state of vigilance and preparedness for care and feeding put a strain on the parents. The time spent awake due to continually waking up and having disrupted sleep that was longer than in families with children of different ages.

“...there are huge individual differences ... and with some it takes an awfully long time before they seem to find any kind of rhythm ... when you know beforehand that maybe I will get two hours' sleep and then I must feed one of them and the feeding may take some time, even an hour, and then feed the other one and stay awake again for two hours, then the other one will be hungry again in two hours ... half a year of poorly slept nights, that takes a toll on your energy...”

The parents' resources and energy diminished gradually. The public-health nurse was contacted frequently because of the infants' sleeping problems and the parents' difficulty in coping.

“...the nights are restless ... what do we do when they eat at hourly intervals and, are crying and sleep for short periods in the daytime, too, and when one wakes up then the other wakes up too ... coping-related issues ... because they do not get any sleep themselves at all...”

(4) Illnesses

In the opinion of public-health nurses, the situations in multiple-birth families that differed from ordinary everyday life were special situations, which meant a need for extra support. Illnesses of the children or parents put a strain on the family and lasted longer than with a single child. Two premature babies presented a challenge to their own professional skills. “...so terribly difficult precisely because the usual rhythm just does not work then... illnesses going round and round in both. There may be really long periods in the family without seeing a truly healthy day..."

“...regarding premature babies, the illnesses that they have or those situations, I do not know anywhere near as much as the parents...”

(5) Speech development

If the child has a delay in their speech development, the public-health nurse recommends day care, where children can hear more speech and have more company than at home. This also prevents hearing and using speech by child. The advice is the same as parents in different ages.

“....if there are two year-old twins and there is problems in speech development or something else, so of course we can recommend to the day care..."

(6) Couple relationship

A public-health nurse raised the issue that parents in multiple-birth families are advised to initially only concentrate on the needs of the children rather than those of the parents. In an experience of human relations, one public-health nurse recommended sometimes meeting parents without the children. This also provides a possibility for a moment for the public-health nurse to discuss with parenthood and the couple's relationship with each other with the parents. Through lived bodily and human relations this meant a safe and confidential professional relationship with the parents. Usually there was no possibility or even time to do this when the children were with the parents.

"When you have parents with one baby, they are reminded about the couple's relationship...with these multiple-birth-family parents it's not often that they are even reminded or it's even mentioned because somehow it seems that it's more important to share the more necessary work between the parents.”

“...if you just have developed a responsible relationship with the parents and have time to discuss 

and the Need for More Training and Education

and so that parents are without the children..."

(7) Demanding sessions

Clinical situations were found to require careful planning and consideration for personal characteristics. However, the meetings were also challenging and demanding sessions for some professionals. The experience of bodily and human relation associated with identifying and addressing a twin by their own name was considered important to the parents. Individual treatment of the child was recognition of the child as a person. Asking and checking a child's name many times during the appointment was considered unprofessional. On visits to the child welfare clinic, parents were amazingly capable of describing very precise personal traits in both their children separately. This showed that they knew their children extremely well, even better than the parents of one child.

"And that, many times, really makes me ashamed, at least as a nurse, if I keep getting confused, asking now are you (child's name) or (other child's name)... And somehow always try to keep something in mind somehow that would help with identifying them."

“... this child is of the kind that he always does ... in character like this and this ... but I never stop being amazed at how, although their life is somehow chaotic, how well they know them right from the beginning. It is to me a quite amazing thing, sometimes it even seems that they know them better than those who only have one baby...”

Public-health nurses experiences of lived body and time were deep when they recognized the night problems but, at the same time, felt that their own opportunities to help parents in finding a day and night rhythm for the infants and help with the parents' and infants' sleep, were very limited. Guidance mainly focused on preparing for the night, joint parental involvement, and changes in the infants' feeding rhythm.

"As a public-health nurse, you cannot really do more than giving guidance on how they should prepare for the night... clear areas of responsibility...It's even been agreed which things you should take care of and which things I'll take care of... multiple-birth-family babies would start sleeping... longer sleep periods, so in that way guiding breastfeeding or bottle feeding."

Some of the nurses recognized this as a stage in their own professional development, and openly acknowledged that the situation of multiple-birth families was special and that the need for training as a professional was immediately in their bodily experience. They highlighted the need for special training in relation to the issues of such families and as an important aspect of their professionalism. It is also a question of professional growth in a temporal process. A public-health nurse discussed her own situation, how true understanding of the life situation can only be achieved through experience, either by living it or seeing it first-hand.

“...since I have not experienced the daily life of a multiple-birth family... I do not know enough about it nor understand the difficulties and problems related to it. In other words, it often feels as though I lack the means to help with those things, some sleeping problems or eating problems, how to handle the situation when there are two of them, and should they be next to each other in the same bed or separate ... and how to do things in actual practice when there are two hungry children, how to deal with that...”

\section{Discussions}

This study aims to describe public-health nurses' experiences of supporting families with twins under five and to contribute to the understanding of working with such families. Eight public-health nurses described their experiences in open interviews and wrote about these afterwards [35]. Phenomenological hermeneutic method has been used, which makes it possible to arrive at new understanding of such families' lifeworld based on the experiences and descriptions of public-health nurses. The results provided new 
understanding on family nursing regarding multiple-birth families, especially the need for support from professionals in their daily life.

The public-health nurses meet multiple-birth families at maternity clinics during the pregnancy and roughly twice at parents' homes after multiple-births, with meetings continuing in the child welfare clinics. Parents appreciated the support and monitoring of the children's growth and development and the information they received about it but they wanted and needed more support [22]. Previous studies have demonstrated general difficulties in managing with multiple children of the same age. Refs. [4, 5, 15, 16, $18,20,22,39]$ being a parent of multiples mean lots of happiness and joy, but also a lot of work, which also takes up a lot of parents' resources. The parents must ensure that they can continue to cope in this full-load life situation, while planning to take care of themselves, too [22, 26]. Ref. [32] states that, when depression, panic attacks, and obsessive-compulsive disorder are not recognized or are left untreated, parents' health, parent-infant interactions, children's development, and family stability may be seriously compromised. Depression or anxiety disorders may affect more than $25 \%$ of multiple-birth parents during the perinatal period. The parents are often uninformed, suffer in silence and fear, and are reticent to seek help. Parents of twins wanted and needed more support to also take care of them and face the challenges of such a life situation [22, 26]. There is also the need for supporting the health of parents, especially mothers [4, $5,15,16,18,20,22]$. Family care workers working in the home state that support and problems in multiple-birth families are intertwined with daily life, and a comprehensive understanding of daily life and the need for support is needed [25].

In a previous study, public-health nurses noticed the different situation and the importance of preparing multiple-birth parents to the new life situation. Support is needed during pregnancy, as well as after the birth of multiple children. Checking the pregnancy is very important to parents but visits to maternity and child welfare clinics should also provide more support for the parenthood of multiples, coping as a parent, and organize family life in daily life. Ref. [16] notices that mothers found it difficult to meet their children's needs simultaneously and that they were more ambivalent than single mothers and singletons. The overloading of the nursing tasks obliges the mother to adopt a precise organization in which she tries not to favor one of the twins to the detriment of the other.

In the current study, a public-health nurse observed unfair treatment between the children in relation to parent-child interaction. It is important for professionals to openly discuss these issues with parents, but also to observe the interaction between parents and children during the meetings in child and wellbeing clinics. Unfair treatment can damage children's health, growth, and development, and professionals cannot neglect these kinds of thing. It is also important to ask parents about their feelings and behaviour. It has also been noticed in previous studies that parents of multiples have problems with individualization and equal treatment $[1,18,20,46$, 47]. Ref. [1] states that nurses can provide concrete, relevant information to assist mothers in developing a healthy attachment with twins. Nurses can play an integral role in assisting these families by developing a therapeutic relationship with them in order to provide emotional support. Ref. [27] states the need to educate parents about the issues related to taking care of multiples as well as the importance of having peer-support.

Ref. [6] notes the complexity of the relationships between a mother and each of her multiple-birth children, and to a lesser extent, between the children themselves. Mothers clearly expressed concern over the difficulties facing their children, arising from their multiple statuses. The mothers feel that they may never be able to satisfy each child fully [31], and, during the first year, the burden of maternal tasks and the increase in baby care leaves little time for starting 
a relationship [46].

In the current study, the advice and support regarding twins' speech development was general. Parents of twins need to support their children's speech development, understand the value of face-to-face contact with each child, use slow speech and reading, and provide opportunities for speech to each child in turn. It is also important for them to understand the inter-twin relationship. It is important for information and advice about this to be provided by social-and health-care professionals. Twins' verbal development is known to be slightly delayed because of the risk situation in pregnancy; sharing their mother's attention with the other twin reduces dyadic verbal communication with adults. Mothers generally address both twins at once and, in doing so, they may offer their twins a less conversationally responsive linguistic environment [41].

There is a need for information and support in treating twins as individuals and parents giving them individual attention from the beginning. It is also important to support parents to devote adequate time to each twin separately, talking to and maintaining eye contact with the individual. Such sessions complement time spent with both twins simultaneously. These had strong interactions with the mothers' own emotional wellbeing. In middle adolescence, puberty appeared to be the most difficult phase for twins, with some exhibiting depressive and psychosomatic or somatic symptoms. Mutual dependence influences twins' social interactions, leisure activities, and, later, their psychiatric and psychosomatic wellbeing [51]. This dependence was deeper in female identical twins [44].

Everyday life for multiple-birth families was productive and full of activity, and the questions that parents had to face were concerned with objectivity and a sense of justness, as well as feelings of inadequacy, being thankful, and being in flux. The lack of both sleep and a daily rhythm were considered demanding and harmful. The help of outside and peer support could be organized already during the pregnancy [20-22]. Ref. [30] investigated themes including confusion over high-risk pregnancy, learning to manage three babies, gathering support and creating a community, adjusting relationships and responsibilities, and opportunities to strengthen triplet families. There are assumptions that conflict with reality, as well as worries and concerns that impact on the self and sources of support. Mothers worried about preterm birth and the effect of the multiple-birth on their family life, including health and wellbeing, and other issues included coping with the gap between the support needed and that received [18].

When the parents are in a multiple-birth situation for the first time it is not easy to ask the right questions. It is important for professionals to provide concrete advice, by asking parents the way to do things and, where possible, giving some examples to help to continue in daily life situations. For example, public-health nurses could be more open about how to take care of twins when both of them are crying or need feeding, how to help child to wait their own turn, such as using music, signing, toys and the mother can rock the (other child's) baby carriage with her foot while breastfeeding her twin. Deep understanding can also develop in situations where the professional can see and be involved in the multiple-birth family's life through concrete experiences, such as when family care workers work in the homes of such families. Primarily only meeting parents at offices in childcare clinics is totally different from that of meeting them at home, where it is possible to see different kinds of situations and to provide support in a real context [22, 25].

In the current study, the public-health nurses had knowledge, however, to a large extent, it was knowledge concerning families with children of different ages, which the nurses did their best to apply to the special situation of multiple-birth families. They have some concrete examples for multiple-birth family support, like recognizing the differences between twins and supporting individuality by 
encouraging different kinds of interests. The public-health nurses tried to give their deep understanding of the daily life and the need for support in such families by being present, listening to parents, showing empathy, and giving advice. However, the support was not very systematic and some of the professionals have little experience meeting such families. There were special requests for advice and support concerning taking care of two children of the same age, including on feeding them, putting them to bed, supporting their individuality, offering support during the children's different stages of growth and development, and organizing regular life at home. Peer support is useful but it cannot compensate for the support of social-and health-care professionals, which should be based on evidence-based nursing practice [20, 22, 25]. Ref. [34] finds that preparation for parenting multiple-birth children should include, for example, education, health promotion, and risk modification strategies, infant care and feeding, child development, and advice on securing help and support. In the current study, visiting the public-health nurse was, nevertheless, considered important. Ref. [18] states the need for health care professionals to be better informed about the advice and support needed by these families.

The public-health nurses have observed that insufficient sleep and sleep debt put a significant strain on parents' resources in multiple-birth families. However, they did not seem to have specific parenthood advice for multiple-birth families where two infants were calling and in need of attention. Lack of sleep consumes a parent's resources and makes it difficult to cope [20, 22, 25, 26, 45]. Parents should be advised to sleep when the infants are asleep and actively arrange for help to allow them to rest, since twins seldom sleep at the same time, making it difficult for parents to get enough sleep [13, 20, 22]. Mothers, in particular, should be advised to rest and sleep whenever is possible [12, 20, 22, 25]. It has been shown that fathers of twins sleep less than mothers for two weeks after taking their babies home. No differences have been observed between parents' morning and evening fatigue [12] but there are differences in how a parent settles and falls asleep after waking up [12, 20,22]. This is also an important subject to discuss because one parent often continues to take care of the children while another has to go to work after a poor night's sleep. Family-centered interventions, such as arranging childcare, ease the family's situation and have a positive impact on parental well-being [49].

Ref. [13] found that parents attempted very different strategies to obtain sleep. These strategies related to their own behaviors and actions, such as taking turns to sleep, sleeping when the babies were asleep, taking daytime naps whenever possible, and getting help from relatives. For the first six months, they also attempted to get the twins on the same feeding/sleeping schedule, to avoid the infants having naps late in the evening (after 6:00 pm), and to keep the infants up late (bedtime at 11:00 pm or later). Mothers were more likely than fathers to sleep when both infants slept, to sleep in the infants' room, and to catch up on sleep during the weekend. In addition, the environment was taken into account by lowering the noise level and the lighting, allowing the babies to sleep elsewhere than in the crib, and playing music. In issues related to waking up and sleep problems, parents can try soothing the infants and having them sleep in different rooms for a time when both parents are involved in night care. If twins stay awake at night, there is clearly a greater need for outside help and family nursing care, which may also be required at night. Already during pregnancy, it is important for professionals to urge multiple-birth families to arrange for help after the babies are born. Later, finding a rhythm for only one of the twins, say, has been found to make daily life easier and give parents the strength to cope $[18,22]$. This study revealed that parents sought and requested help with infants' sleeping problems, but getting their voice heard was also 
difficult. When the new life situation has settled and a rhythm has been found, the parents' feeling that they could manage independently increased, strengthening the positive experience of parenthood [22].

In the current study, the need for feeding advice from public-health nurses was not stressed. The mothers had a very positive attitude towards breastfeeding and needed advice and support by professionals, although, contrary to their expectations, they received only little encouragement from professionals [22]. This corroborates the findings of previous studies. In previous studies, feeding more than one baby was considered physically and psychologically challenging $[17,19,20,22,33,42$, 46], however, despite the childcare pressures, the mothers of twins are eager to breastfeed and pump milk for their newborns. Not all mothers, however, want to breastfeed, due to practical problems [31]. The demands of the situation have been found to be increased by different behavior in the twins. One twin wakes up by herself and is hungry and active, whereas the other perhaps has to be continually woken up, suckles weakly, eats poorly, is tired, and falls asleep during breastfeeding [42]. Mothers of twins also have difficulty in remembering which baby was fed last. This is thought to be connected with stress and the difficulty of identifying the twins as individuals at a very early stage [31]. The success of breastfeeding can be promoted through a good plan, providing support and education. It should particularly focus on the first six weeks after birth. The duration of breastfeeding may also have a connection with maternal depression, in which case, breastfeeding will be stopped earlier. The mothers who are able to persist with the difficulties of establishing a milk supply for twins and feeding two infants are able to continue providing a high percentage of the infants' feedings as breast milk [11]. Breastfeeding support can be given by finding the right breastfeeding position, breastfeeding counseling, and activating the baby by stroking its cheek and waking it up, but also by finding the right rhythm [42]. The opportunity for peer support should also be considered [34].

Some of the nurses recognized this as a stage in their own professional development and openly acknowledged that the situation of multiple-birth families was special and that the need for training as a professional was immediate. The nurses felt that they provided support but that the need for support was much greater than the child welfare clinic was able to meet. Such families are entitled to receive appropriate information to their situation in life, which may involve, for example, improving the well-being and health of the entire family and parenting more than one child of the same age while focusing on supporting their individual growth and development [28, 48]. Recognizing one's own state of professional development is a good beginning to continue more education and training.

Temporal understanding is important when giving advice to parents. This requires understanding the multiple-birth-family lifeworld, and giving the advice which is most needed, for example, taking care of babies, feeding them, and putting them to bed are the basic needs to initially organize daily life. Question of putting children into the same or different groups can come later. The social-and health-care professionals in different areas have a vital role in supporting multiple-birth families but they need special knowledge [9, 14, 18, 20, 22]. Moreover, professionals are vital to assess the needs of such families, coordinating various services and providing ongoing support [9].

\section{Conclusions}

In the current study, support focused on the individual situation of multiple-birth families is a challenge to professionals and the need to develop family nursing care is important. Multiple-birth families should receive more attention and different kind of support, including emotional, practical, informative, and peer support from professionals. 
Developing multi-professional teams, working together, learning from each other, and participating in special education are important for understanding and supporting multiple-birth families. This also includes hearing the voices of parents.

Simulation pedagogy could also lead to mutual learning, where real situations can be imitated and solved together by professionals. This provides more specific tools for professionals to co-operate and, later, to provide advice and support to multiple-birth families. Well-being and heath in multiple-birth families' means support parents and parenthood in order to promote children's health, wellbeing, growth, and development, as both individuals and twins.

\section{Limitations}

Phenomenological hermeneutic studies enable natural enquiry into real contexts. Being unique, individual experiences do not lend themselves to generalization. The size of the sample is small $(\mathrm{n}=8)$, it is enough, the data collection has been done carefully and this sample produced very rich experiential material. This paper explores general support extended to multiple-birth families during the time professionals meet parents. It did not focus, for example, on the time of pregnancy or one year after birth of twins. There is lack of research on this topic to compare the phenomena which of professionals provide to multiple-birth families.

\section{Acknowledgments}

The author wishes to thank all the participants, parents of twins and social and health care professionals for sharing their experiences and life for participation in this research.

\section{Declaration of Conflicting Interests}

The author(s) declared no potential conflicts of interest with respect to the research, authorship, and/or publication of this article. The first author discloses the receipt of the following financial support for the research: Ministry of Social Affairs and Health.

\section{References}

[1] Anderson, A., and Anderson, B. 1990. "Toward a Substantive Theory of Mother-Twin Attachment. MCN.” The American Journal of Maternal/ Child Nursing 15: 373-7.

[2] Ball, H. L. 2006. "Caring for Twin Infants: Sleeping Arrangements and Their Implications.” Evidence Based Midwifery 4 (1): 10-6.

[3] Ball, H. L. 2007. "Together or Part? A Behavioural and Physiological Investigation of Sleeping Arragements Fot Twin Babies. Caring for Twin Infants: Sleeping Arrangements and Their Implications." Evidence Based Midwifery 23 (4): 404-12.

[4] Beck, C. T. 2002. "Mothering Multiples. A Meta Synthesis of Qualitative Research. MCN.” The American Journal of Maternal and Child Nursing 27: 214-22. PMID: 12131272

[5] Beck, C. T. 2002. "Releasing the Pause Button. Mothering Twins during the First Year of Life." Qualitative Health Research 12 (5): 593-608. PMID: 11993558.

[6] Bolch, C. E., Davis, P., Umstad, M. P. and Fisher, J. R. 2012. "Multiple Birth Families with Children with Special Needs: A Qualitative Investigation of Mothers' Experiences.” Twin Res Hum Genet 15 (4): 503-15. doi: 10.1017/thg.2012.24.

[7] Bryan, E. 2002. "Educating Families, before, during and after a Multiple Birth.” Semin Neonatal 7: 241-6.

[8] Bryan, E. 2003. "The Impact of Multiple Preterm Births on the Family." An International Journal of Obstetrics and Gynaecology 110 (20): 24-8.

[9] Bryan, E. 2008. "Multiple-Birth Children and Their Families. What Nurses Need to Know." AWHONN Lifelines 10 (2): 138-44. PMID 16712576.

[10] Cohen, M. Z., Kahn, D., and Steeves, R. 2000. "Hermeneutic Phenomenological Research: A Practical Guide for Nurse Researchers.” Thousand Oaks, California: Sage.

[11] Damato, E. G., Dowling, D. A., Madigan, A., and Thanattherakul, C. 2005. "Duration of Breast Feeding for Mothers of Twins.” Journal of Obstetric, Gynecologic \& Neonatal Nursing $34 \quad$ (1): $\quad$ 201-9. Doi:10.1177/0884217504273671.

[12] Damato E. G., and Burant, C. 2008. "Sleep Patterns and Fatigue in Parents of Twins.” JOGNN 37: 738-49. Doi: 10.111/j.1552-6909.2008.00296.

[13] Damato, E. G., and Zupancic, J. 2009. "Strategies Used by Parents of Twins to Obtain Sleep.” App Nurs. Res. 22 (3): 216-20. 

and the Need for More Training and Education

[14] Denton, J. 2005. “Coping after Multiple Birth. Twins and More-Practical Aspects of Parenting in the Early Years.” Journal of Family Health Care 15 (6): 173-6. PMID: 16447884

[15] Garel, M., and Blondel, B. 1992. “Assessment at 1 Year of the Psychological Consequences of Having Triplets.” Human Reproduction 7 (5): 729-32. PMID: 1639994

[16] Goshen-Gottstein, E. R. 1980. "The Mothering of Twins, Triplets and Quadruplets.” Psychiatry 43: 189-204. PMID: 7403379

[17] Gromada, K. K. and Spangler, A. 1998. "Breastfeeding Twins and Higher-Order Multiples.” Journal of Obstetric, Gynecologic, and Neonatal Nursing 27: 441-9. PMID: 9684207

[18] Harvey, M. E., Athi, R., and Denny, E. 2014. "Exploratory Study on Meeting the Health and Social Care Needs of Mothering with Twins.” Community Practitioner 87 (2): 28-31. PMID: 24597136

[19] Hattori, R., and Hattori, H. 1999. "Breastfeeding Twins: Guidelines for Success.” Birth 26 (1): 37-42. PMID: 10352054.

[20] Heinonen, K. 2004. Dimensions and Possibilities in Multiple Birth Parenthood. University of Kuopio. Abstract in English. Finland: Kopijyvä. Kuopio.

[21] Heinonen, K., Pietilä, A. M., and Moilanen, I. 2007. "Experiences of Support by Parents of Multiple Birth Children-An Interview Study. Nursing Science.” Hoitotiede 4: 223-35. Abstract in English.

[22] Heinonen, K. 2013. "The Lifeworld of Multiple-Birth Families from Being on Guard to Strengthening Parenthood.” Phenomenological-Hermeneutic Study. Publications of the University of Eastern Finland. Dissertation in Health Sciences. Abstract in English.

[23] Heinonen, K. 2015a. "Levels of Reduction in Van Manen's Phenomenological Hermeneutic Method: An Empirical Example.” Nurse Researcher 22 (4): 20-4. Doi 10.7748

[24] Heinonen, K. 2015b. "Methodological and Hermeneutic Reduction-A Study of Finnish Multiple-Birth Families.” Nurse Researcher 22 (6): 28-34. Doi 10.7748.

[25] Heinonen, K. 2016. "Supporting Multiple Birth Families at Home.” International Journal of Caring Science 9 (2): 422-31.

[26] Heinonen, K., Häggman-Laitila, A., Moilanen, I., and Pietilä, A. M. 2016. “The Lifeworld of Multiple Birth Families.” International Journal of Caring Science 9 (3): 754-69.

[27] Holditch-Davis, D., Roberts, D., and Sandelowski, M. 1990. "Early Parental Interactions with and Perceptions of Multiple Birth Infants.” Journal of Advanced Nursing 30 (1): 200-10. PMID: 10403997

[28] ICOMBO 2017. International Council of Multiple-Birth
Organisations. Retrieved fromhttp://icombo.org/. 2.5.2017.

[29] Jahanafar, S. 2012. “Twins Co-bedding at Home. Parents' Perspective, Sleeping Pattern and Developmental Millstone.” Medical Journal 13 (1): 13-8.

[30] Jenkins, D., and Coker, R. 2010. "Coping with Triplets: Perspectives of Parents during in First Four Years.” Health \& Social Work 35 (3): 169-80.

[31] Josse, D., and Robin, M. 1986. "Some Aspects of Mother-Child Relationships Following the Birth of Twins.” Early Child Development and Care 26: 1-18.

[32] Leonard, L. G. 1998. "Depression and Anxiety Disorders during Multiple Pregnancy and Parenthood.” JOGGNN. 27 (3): 329-37. DOI 10.1111/j. 1552-6909.1998.tb02656.x.

[33] Leonard, L. G. 2000. "Breastfeeding Triplets. The at Home Experience.” Public Health Nursing 17 (3): 211-21.

[34] Leonard, L. G., and Denton, J. 2006. "Preparation for Parenting Multiple Children.” Early Human Development 82 (6): 371-8. PMID: 16675166.

[35] Van Manen, M. 1997. Researching Lived Experience. Human Science for an Action Sensitive Pedagogy. London: Ont: Althouse.

[36] Van Manen, M. 2014. Phenomenology of Practice. Meaning-Giving Methods in Phenomenological Research and Writing. USA: Left Coast Press.

[37] Van Manen, M., and Adams, C. A. 2010. “Phenomenology.” Edited by Peterson, P., Baker, E., and McGaw, B. In International Encyclopaedia of Education (pp. 449-55). Oxford: Elsevier.

[38] Van der Zalm, J. E. 1995. “Accommodating a Twin Pregnancy: Maternal Processes.” Acta. Genet. Med. Gemellol. 44: 117-33. PMID: 8750776.

[39] McKenzie, P. 2006. "The Seeking of Baby-Feeding Information by Canadian Women Pregnant with Twins.” Midwifery 22: 218-27. PMID: 16697092.

[40] Moilanen, I. 1996. Kaksosuus. In: Räsänen E. Moilanen I. Tamminen T. \& Almqvist F. (toim.). Lasten ja nuorisopsykiatria. Duodecim. Cummerus Kirjapaino Oy. Jyväskylä, 72-5. Finnish.

[41] Moilanen, I., Kunelius, A., Tirkkonen, T., and McKinsey Grittenden, P. 2003. "Attachment in Finnish Twins.” In Grittenden. P. McKinsey, Grittenden, P., and Claussen, A. H. (Edit.). The Organization of Attachment Relationships Maturation, Culture and Context, 125-40. Cambridge: Cambridge University Press.

[42] Nyqvist, K. H. 2002. "Breastfeeding in Preterm Twins: Development of Feeding Behavior and Milk Intake during Hospital Stay and Related Caregiving Practices.” Journal of Pediatric Nursing 17 (4): 246-56.

[43] Olivennes, F., Golombok, S., and Ramogida, C. 2005. "Behavioral and Cognitive Development As Well As 


\section{and the Need for More Training and Education}

Family Functioning of Twins Conceived by Assisted Reprobuction: Findings from a Large Population Study.” Fertility and Sterility 84 (3): 725-33.

[44] Penninkilampi-Kerola, V. 2006. Implications of Co-twin Dependence for Twins' Social Interactions, Mental Health and Alcohol Use. A Follow-up Study of Finnish Twins from Adolescence to Early Adulthood. Helsinki: University of Helsinki.

[45] Polit, D. F., and Beck, C. T. 2006. Essentials of Nursing Research. Methods, Appraisal, and Utilization. 6th edition. Philadelphia: Lippincott Williams \& Wilkins.

[46] Robin, M., Josse, D., and Tourette, C. 1988. "Mother-Twin Interaction during Early Childhood.” Acta. Geneticae Medicae et. Gemellologiae 37 (2): 151-9.

[47] Robin, M., Corroyer, D., and Casati, I. 1996. "Childcare Patterns of Mothers of Twins during the First Year.” J. Child Psychology and Psychiatry 37 (4): 435-60. PMID:
8735445.

[48] The Finnish Multiple-births Association. 2017. Retrieved from http://www.suomenmonikkoperheet.fi/monikkotietoa/1.6. 2017.

[49] Thome, M., and Skuladottir, A. 2005. "Evaluating a Family-Centered Intervention for Infant Sleep Problems.” Journal of Advanced Nursing 50 (1): 5-11.

[50] Tirkkonen, T. 2015. Early Attachment, Mental Well-being and Development of Finnish Children at Preschool Age. Twinship-Risk or Opportunity? University of Oulu. Graduate school. Oulu Tampere: Juvenes Print.

[51] Trias, T. 2006. Inter-twin and Parent-twin Relationships and Mental Health: A Study of Twins from Adolescence to Young Adulthood. University of Oulu. Oulu: Juvenes Print Tampere. 